\title{
BIOCOMPATIBILIDADE EM FILMES DE HIDROXIAPATITA REFORÇADA COM NANOTUBOS DE CARBONO
}

\author{
Natália Marassi Martinelli ${ }^{1}$ \\ Mara Julia Galera ${ }^{2}$ \\ Miller de Almeida Marques ${ }^{3}$ \\ Ritchelli Ricci ${ }^{4}$ \\ Anderson de Oliveira Lobo ${ }^{5}$ \\ Fernanda Roberta Marciano 6
}

Resumo: As características químicas e estruturais individuais de nanotubos de carbono (NTC) e hidroxiapatita (HAp), principal constituinte da fase inorgânica do osso, possibilitam seu uso na área médica como materiais biocompatíveis em implantes e próteses. O objetivo deste trabalho é estudar a biocompatibilidade do compósito HAp/NTC eletrodepositadas comitantemente em aço 316. Para a produção dos compósitos os NTC foram dispersos na solução eletrolítica em concentrações de $1 \%$ e $3 \%$. Os resultados obtidos in vitro, utilizando o ensaio da Lactato Desidrogenase (LDH), demostraram que nenhuma amostra causou citotoxicidade nas células osteoblásticas. Neste estudo, também foram avaliados genes relacionados à osteogênese, tais como: fosfatase alcalina (ALP), osteopontina (OPN), osteocalcina (OC) por RT-qPCR (Transcrição Reversa - Reação em Cadeia da Polimerase quantitativa), após 14 dias. Os osteoblastos em contato com a HAp/NTC apresentaram aumento da expressão de genes importantes no processo de mineralização e maturação óssea. Os resultados demonstraram um grande potencial de aplicação clínica deste compósito.

Palavras-chave: Nanotubos de carbono; Hidroxiapatita; Eletrodeposição; Osteoblastos; Expressão genica.

\footnotetext{
${ }^{1}$ Engenharia Química/Universidade do Vale do Paraíba, Brasil. E-mail: natalia_marassi@hotmail.com.

2 Engenharia Química/Universidade do Vale do Paraíba, Brasil. E-mail: mariajuliagalera1@hotmail.com.

${ }^{3}$ Engenharia Biomédica/Universidade do Vale do Paraíba, Brasil. E-mail: miller_marques_1993@hotmail.com. ${ }^{4}$ Pós-doutorado em Nanotecnologia Biomédica/Universidade do Vale do Paraíba, Brasil. E-mail: ritchelli@gmail.com.

${ }^{5}$ Nanotecnologia Biomédica/Universidade do Vale do Paraíba, Brasil. E-mail: aolobo@univap.br.

${ }^{6}$ Nanotecnologia Biomédica/Universidade do Vale do Paraíba, Brasil. E-mail: frmarciano@univap.br.
} 